\title{
Aspectos da mão de obra contratada e qualidade do leite em propriedades leiteiras localizadas no sul de Minas Gerais
}

\author{
[Aspects of hired labor and milk quality from dairy farms located in the south of Minas Gerais]
}

\section{"Artigo Científico/Scientific Article"}

\author{
Marcel Gomes Paixão ${ }^{1 *}$, Marcos Aurélio Lopes ${ }^{2}$, Ronaldo Carvalho Macedo ${ }^{3}$, \\ Geraldo Márcio da Costa $^{2}$, Luiz Ronaldo de Abreu ${ }^{1}$, Sandra Maria Pinto ${ }^{1}$
}

\author{
${ }^{1}$ Departamento de Ciência dos Alimentos, Universidade Federal de Lavras, Lavras - MG, Brasil \\ ${ }^{2}$ Departamento de Medicina Veterinária, Universidade Federal de Lavras, Lavras - MG, Brasil. \\ ${ }^{3}$ Cia do Leite, Lavras - MG, Brasil. \\ *Autor para correspondência/Corresponding author: E-mail: marcelgpaixao@gmail.com
}

\section{Resumo}

Objetivou-se analisar alguns aspectos socioeconômicos e comportamentais, local de trabalho e direitos trabalhistas de 37 ordenhadores considerados contratados provenientes de 28 propriedades leiteiras localizadas em seis municípios da região sul de Minas Gerais, por meio da aplicação de formulário semiestruturado durante os horários de ordenha. Verificou-se a relação de frequência entre os aspectos verificados e as médias das análises de contagem bacteriana total (CBT) (superiores a 100.000 UFC/mL) e contagem de células somáticas (CCS) (superiores a 600.000 células/mL) do leite dos tanques. Constatou-se que a maioria das propriedades leiteiras estudadas utilizavam sistema de produção do tipo semi-intensivo, com duas ordenhas diárias, realizadas em ordenhadeiras do tipo balde ao pé e sistema de refrigeração em tanques de expansão; produção superior a 151 litros de leite/dia e no máximo 20 litros de leite/vaca/dia. No total, $89 \%$ e $57 \%$ das propriedades apresentaram médias inferiores aos limites da legislação para CBT e CCS, respectivamente. As questões relacionadas com a tecnificação das propriedades estudadas (tanto alto, quanto baixo) e, algumas questões referentes às características do local de trabalho, comportamentais e direitos trabalhistas dos ordenhadores contratados e substitutos ("folguistas"), apresentaram uma relação com a qualidade higiênico-sanitária do leite produzido, pois, em geral, nas propriedades em que tais questões não condiziam com o preconizado, as médias de CBT e CCS apresentaram-se com maiores frequências superiores aos limites estabelecidos.

Palavras-chave: condições de trabalho; células somáticas; contagem bacteriana; exploração leiteira.

\begin{abstract}
This study had the objective of analyzing some socioeconomic and behavioral aspects, workplace and labor rights of 37 contracted milkers from 28 dairy farms located in six counties of the southern region of Minas Gerais State, through application of a checklist during the milking routine. The frequency ratio between the evaluated aspects and the means for total bacterial count (TBC) (greater than 100,000 CFU/mL) and somatic cell count (SCC) (greater than 600,000 cells/mL) analyses of bulk tank milk were then correlated. We identified that the majority of farms had a semi-intensive production system, with two daily milkings (carried out in automatic milking buckets) and bulk tanks were the predominant milk cooling system; a daily milk production greater than 151 liters of milk/day with a maximum production of 20 liter/per cow/day were also identified. Respectively $89 \%$ and $57 \%$ of farms had TBC and SCC means below the legislation limits. Aspects related to technification parameters within farms (both high and low), and some aspects associated with the characteristics of the workplace, labor rights, and behavior of milkers and substitute milkers (weekend labor) had a relationship with the quality of milk produced. Generally, in farms where these aspects were not in agreement with the recommendations, we identified a greater incidence of bulk tank milk TBC and SCC means above the legislation limits.
\end{abstract}

Keywords: working conditions; somatic cell; bacterial count; dairy farming. 


\section{Introdução}

O termo "qualidade do leite" ganhou enfoques diferentes e envolve não apenas as características inerentes ao produto, mas também as particularidades do processo produtivo, incluindo bem-estar animal, questões humanitárias, ambientais, econômicas e políticas. Conhecer e respeitar cada componente do processo produtivo é uma tarefa do profissional do campo e também uma das diferenças entre o sucesso e o fracasso da atividade leiteira.

O padrão tecnológico agrícola atual tem levado à absorção de um volume expressivo de mão de obra, tanto no meio rural quanto no meio urbano; porém, tal demanda é por mão de obra qualificada, que ainda é escassa no Brasil (Alves et al., 2005). No caso da pecuária leiteira, em específico a ordenha dos animais, os procedimentos de qualificação devem ser mais exigentes ainda, pois as atitudes dos responsáveis refletem em outros elos da cadeia de produção e processamento do leite e derivados lácteos.

Por outro lado, poucos são os estudos sobre os direitos trabalhistas no meio rural brasileiro, e caso esses direitos não sejam obedecidos, cria-se um vínculo empregatício informal, desmotivando os trabalhadores e "desprofissionalizando" a atividade agrícola do país. De acordo com a Constituição Brasileira de 05 de outubro de 1988, o direito dos trabalhadores rurais e urbanos são igualmente consolidados no artigo $7^{\circ} \mathrm{e}$ incisos de tal documento (BRASIL, 1988).

Diversas pesquisas têm enfatizado a importância das práticas de manejo e da influência do comportamento dos ordenhadores para a maximização da produção, bem-estar animal e qualidade higiênico sanitária do leite produzido (Souza et al., 2005; Arcuri et al., 2006; Coentrão et al., 2008; Elmoslemany et al., 2009). Porém, a relação entre a qualidade higiênico sanitária do leite produzido e os aspectos relacionados à gestão de pessoas, ou seja, direitos trabalhistas, boas condições de trabalho, valorização do trabalho e questões socioeconômicas dos ordenhadores contratados, até o momento, não foram encontrados na literatura.

Diante do exposto, objetivou-se analisar alguns aspectos socioeconômicos e comportamentais, local de trabalho e direitos trabalhistas de ordenhadores considerados contratados e a relação com a qualidade higiênicosanitária do leite produzido em propriedades localizadas em seis municípios da região sul de Minas Gerais.

\section{Material e Métodos}

Elaborou-se um formulário semiestruturado contendo 41 questões referentes aos aspectos gerais de produção, aspectos socioeconômicos, condições de trabalho, comportamento e direitos trabalhistas de ordenhadores contratados, o qual foi aplicado, em dezembro de 2011, a 37 ordenhadores de 28 propriedades distribuídas em seis municípios (Bom Sucesso $-\mathrm{n}=5$; Ibituruna $-\mathrm{n}=2$; Ijaci $-\mathrm{n}=10$; Itumirim $-\mathrm{n}=5$; Lavras $-\mathrm{n}=4$; Ribeirão Vermelho - $n=2$ ) localizados na região do Alto Rio Grande, sul do estado de Minas Gerais. As informações que necessitavam de checagem foram obtidas durante a realização da ordenha, e as que necessitavam de resposta direta dos ordenadores, após a ordenha.

Os dados foram transcritos em planilhas eletrônicas desenvolvidas especificamente para esse fim, utilizando o software Microsoft Excel $^{\circledR}$ $14.0 \mathrm{e}$, posteriormente, realizou-se o agrupamento das respostas por meio de categorização e frequência, conforme Bardin (2003). Os dados categóricos (qualitativos) foram transcritos de acordo com seu código de categoria no questionário. Em caso de questões abertas e dados quantitativos, esses eram digitados categorizados.

Para os valores referentes às médias das análises de contagem de células somáticas (CCS) e contagem bacteriana total (CBT) do leite dos tanques foram utilizados dados de um intervalo de 12 meses, seis meses antes e seis após o término da aplicação do questionário, visando a obtenção de uma média com maior representatividade da qualidade higiênico sanitária do leite nesse intervalo. Nos casos em que os produtores deixaram de vender o leite para a empresa, foram utilizados os resultados das análises referentes aos 12 meses anteriores. As amostras de leite dos tanques dos produtores eram coletadas pela equipe responsável pela qualidade do leite do laticínio, devidamente acondicionadas e enviadas à Clínica do Leite, da Escola Superior de Agricultura "Luiz de Queiroz" (ESALQ/USP), pelo menos uma vez por mês. As análises de CCS foram efetuadas em equipamento eletrônico Bentley Combi System $2300^{\circledR}$ e a avaliação da CBT foi realizada em equipamento eletrônico IBC BactoCount ${ }^{\circledR}$ (Bentley Instruments Incorporated, Chaska, Estados Unidos da América). 
Para a comparação de frequências entre as questões verificadas e a qualidade higiênicosanitária do leite dos tanques dos produtores os resultados das médias das análises foram agrupados nos seguintes limites, respectivamente, para CBT e CCS: $100.000 \mathrm{UFC} / \mathrm{mL}$ (com 68\% e $32 \%$ dos produtores com médias inferiores e superiores a esse limite, respectivamente; 600.000 células/mL (limites legais para o período em estudo) (BRASIL, 2011) (com 57\% e 43\% dos produtores com médias inferiores e superiores a esse limite, respectivamente. Para a contabilização e determinação das porcentagens de frequências das respostas do formulário utilizou-se o software SPSS Statistics ${ }^{\circledR} 17.0$ (SPSS, 2008).

\section{Resultados e Discussão}

As análises referentes a qualidade higiênicosanitária do leite apresentaram $89 \%$ e $57 \%$ das médias inferiores aos valores limites para a legislação no período estudado (2011) (600.000 UFC/mL e células/mL) (BRASIL, 2011) para CBT e CCS, respectivamente. As médias gerais foram de 271.000 (UFC/mL) ( \pm 613.000) e 572.000 (células somáticas $/ \mathrm{mL})( \pm 238.000)$.

A maioria das propriedades leiteiras estudadas utilizavam sistema de produção do tipo semi-intensivo, com duas ordenhas diárias, realizadas em ordenhadeiras do tipo balde ao pé e sistema de refrigeração em tanques de expansão; produção superior a 151 litros de leite/dia e no máximo 20 litros de leite/vaca/dia (Tabela 1). Verificou-se que todos produtores que utilizavam apenas uma ordenha diária, ou possuíam ordenha manual, ou sistema de refrigeração em tanques de imersão, ou produziam até 151 litros de leite/dia possuíam as médias de CBT superiores ao limite estabelecido em estudo e ao padrão atual previsto para o ano de 2016 (Brasil, 2011) (300.000 $\mathrm{UFC} / \mathrm{mL}$ ).

Em estudo realizado por Milani et al. (2016), analisando 1.733 resultados de análises de CBT do leite provenientes de 326 propriedades com diferentes níveis de tecnificação e sistemas de produção (38 especializados, 78 semiespecializados e 210 não especializados), verificou-se que, respectivamente, $48,5 \%, 77,8 \% \mathrm{e}$ $86 \%$ das amostras estavam fora dos padrões da Instrução Normativa $\mathrm{n}^{\circ} 51$ de $2002(750.000$ UFC/mL) (BRASIL, 2002), para especializado, semi-especializado e não especializado. No presente estudo, os produtores com nível de tecnificação baixo (ordenha manual, tanque de imersão, uma ordenha diária e até 150 litros por dia) apresentaram maiores médias para CBT; porém, apenas $10,7 \%$ (3) em discordância com o limite da legislação do período estudado (600.000 $\mathrm{UFC} / \mathrm{mL}$ ) (BRASIL, 2011). Tal resultado refletiu a não especialização dos produtores, pois o valor estabelecido (100.000 UFC/mL) era o limite para a máxima bonificação do leite por CBT, praticada por vários laticínios da região em estudo.

Das nove propriedades que utilizavam ordenhadeira do tipo leite canalizado, $88,8 \%$ (8) apresentaram as médias de CCS superiores ao limite estabelecido pela legislação (Tabela 1). De acordo com Mein et al. (2012), a relação do bom funcionamento do equipamento de ordenha com a incidência de mastite é difícil de ser medida e, estimativas mais recentes apontam que a ordenhadeira mecânica apresenta efeitos diretos e indiretos e que, conjuntamente, podem estar relacionados com uma parcela de novos casos de mastite em um rebanho, variando de 6,0 a 20,0\%.

$\mathrm{Na}$ Tabela 2 verifica-se os aspectos relativos às características socioeconômicas e do local de trabalho de 37 ordenhadores contratados das 28 propriedades leiteiras localizadas no sul de Minas Gerais e, a frequência dos produtores com valores superiores aos limites de CBT e CCS estabelecidos. Em relação à escolaridade, a maioria relatou que estudou até no máximo o ensino fundamental; porém, $61,3 \%$ não o concluiu. $\mathrm{O}$ baixo nível de escolaridade pode refletir no desconhecimento sobre princípios básicos para a obtenção higiênica do leite, bem como dificultar o melhor aproveitamento em treinamentos e programas de transferências de tecnologias. No presente estudo, em $50 \%$ das propriedades que os ordenhadores não possuíam estudo algum (analfabetismo ou apenas sabiam ler), as médias de CCS e CBT apresentaram-se superiores aos limites estabelecidos; porém, em $100 \%$ das propriedades em que os ordenhadores possuíam o ensino médio completo, as médias de CCS apresentaram-se superiores ao preconizado. Entretanto, deve-se ressaltar que o número total de casos avaliados foi muito baixo (ao total quatro para analfabetismo ou apenas sabiam ler e dois para ensino médio completo), sendo necessários futuros estudos para relacionar tais fatores.

Em relação ao tempo que exerciam a profissão, a maior parcela dos ordenhadores respondeu há 10 anos ou menos (Tabela 2). O tempo exercido pelo ordenhador na atividade sem o devido treinamento pode refletir em excesso de 
confiança, causando resistência e aversão quanto à adoção de novas práticas de ordenha. Porém, no presente estudo, $55,6 \%$ das propriedades nas quais os ordenhadores exerciam a profissão há 20 anos, ou mais, os valores médios de CCS e CBT foram inferiores aos limites estabelecidos, não exercendo uma forte influência na qualidade do leite produzido.

Tabela 1. Características descritivas de produção das 28 propriedades leiteiras analisadas, provenientes de seis municípios do sul de Minas Gerais e a frequência dos produtores com valores superiores aos limites de CBT (contagem bacteriana total) e CCS (contagem de células somáticas) estabelecidos.

\begin{tabular}{|c|c|c|c|c|}
\hline \multirow[b]{2}{*}{ Questão } & \multirow[b]{2}{*}{ Averiguação } & \multirow{2}{*}{$\begin{array}{c}\text { Frequência total } \\
\qquad(n=28)\end{array}$} & \multicolumn{2}{|c|}{$\begin{array}{llr}\text { Frequência } & \text { de produtores } & \text { com } \\
\text { valores } & \text { superiores } & \text { aos } \\
\text { parâmetros } & \text { higiênico-sanitários }\end{array}$} \\
\hline & & & $\mathrm{CBT}^{\mathrm{a}}(\mathrm{n}=11)$ & $\operatorname{CCS}^{\mathbf{b}}(\mathrm{n}=12)$ \\
\hline \multirow[t]{3}{*}{ Sistema de produção } & Regime de pastejo & $10(35,7 \%)$ & $5(50,0 \%)$ & $5(50 \%)$ \\
\hline & Semi-intensivo & $16(57,1 \%)$ & $5(31,2 \%)$ & $7(43,7 \%)$ \\
\hline & Intensivo & $2(7,1 \%)$ & $1(50,0 \%)$ & $0(0,0 \%)$ \\
\hline \multirow[t]{2}{*}{ Frequência de ordenhas/dia } & Uma & $3(10,7 \%)$ & $3(100,0 \%)$ & $1(33,3 \%)$ \\
\hline & Duas & $25(89,3 \%)$ & $8(32,0 \%)$ & $11(44,0 \%)$ \\
\hline Escala de produção diária & $<151$ & $4(14,3 \%)$ & $4(100,0 \%)$ & $2(50 \%)$ \\
\hline \multirow[t]{2}{*}{ (litros de leite) } & 151 a 500 & $13(46,4 \%)$ & $6(46,1 \%)$ & $7(53,8 \%)$ \\
\hline & $>500$ & $11(39,3 \%)$ & $1(9,0 \%)$ & $3(27,3 \%)$ \\
\hline \multirow[t]{3}{*}{ Litros de leite/vaca/dia } & $<10$ & $13(46,4 \%)$ & $6(46,1 \%)$ & $8(61,5 \%)$ \\
\hline & 10 a 20 & $14(50 \%)$ & $5(35,7 \%)$ & $4(28,6 \%)$ \\
\hline & $>20$ & $1(3,6 \%)$ & $0(0,0 \%)$ & $0(0,0 \%)$ \\
\hline \multirow[t]{3}{*}{ Tipo de ordenha } & Manual & $4(14,3 \%)$ & $4(100,0 \%)$ & $1(25,0 \%)$ \\
\hline & Balde ao pé & $15(53,6 \%)$ & $5(33,3 \%)$ & $3(20,0 \%)$ \\
\hline & Canalizada & $9(32,1 \%)$ & $2(22,2 \%)$ & $8(88,8 \%)$ \\
\hline \multirow[t]{2}{*}{ Equipamento de refrigeração } & Imersão & $3(10,7 \%)$ & $3(100,0 \%)$ & $2(66,6 \%)$ \\
\hline & Expansão & $25(89,3 \%)$ & $8(32,0 \%)$ & $10(40,0 \%)$ \\
\hline
\end{tabular}

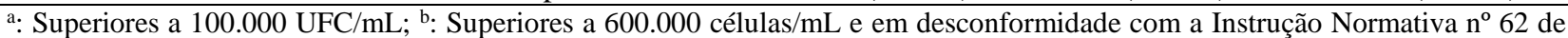
2011 durante o período estudado. Em casos onde o número de frequências difere do total dos casos, houve perda de dados. $(\%)$ : De acordo com as quantidades de casos averiguados, e não do total de casos.

A maioria dos ordenhadores relatou que não foram treinados para exercer a atividade (Tabela 2). Paixão et al. (2014), em estudo sobre o impacto econômico de diferentes níveis de boas práticas agropecuárias referentes a qualidade do leite em uma fazenda constatou que o valor despendido com o treinamento do ordenhador representou apenas $1,3 \%$ do custo total da implantação das boas práticas agropecuárias em seu nível máximo. Verificou-se que, das propriedades nas quais os ordenhadores receberam treinamento, 57,1\% apresentaram as médias de CCS do leite dos tanques superiores ao limite da legislação vigente durante o período estudado (IN62) (BRASIL, 2011) (Tabela 2). Tal fato revelou que apenas o treinamento não garante a qualidade do leite produzido; também são necessários investimentos relativos ao tratamento dos casos de mastite já estabelecidos e principalmente em prevenção de novos casos (Lopes et al., 2011). Em relação aos parâmetros de CBT, em $71,4 \%$ das propriedades em que os ordenhadores receberam treinamento, as médias apresentaram valores inferiores ao limite estabelecido, e os proprietários estariam recebendo as bonificações máximas referentes a esse parâmetro de qualidade no período estudado. Os resultados revelaram que, a presença da mão de obra treinada, em geral, garantia a baixa CBT do leite, pois são tarefas relativamente simples de serem realizadas, e os resultados foram observados imediatamente após o treinamento e aplicação das boas práticas agropecuárias (BPA) para a qualidade do leite e, diferentemente dos programas de controle de CBT, os programas para controle de mastite dependem de tempo e de decisões por parte dos produtores, além de mudanças na forma de administração da propriedade em relação à saúde dos animais.

Constatou-se que, a maioria dos ordenhadores residia na propriedade em que trabalham e, todas as residências possuíam luz e água encanada; porém, quatro não possuíam rede de esgoto. O local de trabalho eram "salas de ordenha" em sua maioria, com água encanada, pias, sanitizantes, toalhas, materiais de limpeza pessoal e banheiros próximos para as necessidades básicas do trabalhador. A presença da rede de esgoto e de materiais adequados para a higiene pessoal do 
ordenhador é importante na prevenção de possíveis contaminações por coliformes, pois as fontes ambientais de contaminação do leite incluem a água utilizada na limpeza do equipamento e em outras tarefas, e as próprias mãos do ordenhador; fontes essas, que são susceptíveis a contaminação, caso não haja uma rede de esgoto e hábitos higiênicos adequados. Além dos aspectos referentes a CBT do leite, é importante ressaltar que microrganismos como bactérias do grupo coliformes e Pseudomonas spp. também estão associados à ocorrência de mastite, decorrentes da limpeza da glândula mamária com água contaminada (Andrews et al., 2008) ou das próprias mãos do ordenhador.

A maioria dos ordenhadores relatou que possuíam todos os materiais necessários para a boa execução do trabalho (Tabela 2). A norma regulamentadora relativa à segurança e higiene do trabalhador rural - NR 31 (Portaria $\mathrm{n}^{\circ}$ 86, de 03 de março de 2005) prevê que o empregador rural deve: garantir adequadas condições de trabalho, higiene e conforto para todos os trabalhadores; promover melhorias nos ambientes e nas condições de trabalho, de forma a preservar o nível de segurança e saúde dos trabalhadores (BRASIL, 2005).

Verificou-se que, nas propriedades do sul de Minas Gerais nas quais os locais de ordenha era o curral descoberto e que estava em desconformidade com a legislação atual em relação a este quesito (IN62) (BRASIL, 2011), a média de CBT foi superior ao limite estabelecido. Além disso, aproximadamente $50,0 \%$ e $66,7 \%$ das propriedades nas quais os ordenhadores relataram que os locais de trabalho não continham pias, sanitizantes e demais materiais de limpeza apresentaram as médias de CBT e CCS superiores ao limite estabelecido (Tabela 2). Em uma propriedade, na qual o ordenhador relatou não possuir todos os materiais necessários para a boa execução de seu trabalho, ambas as médias de CBT e CCS apresentaram-se superiores ao limite estabelecido. De acordo com Jayarao e Wang (1999) as produções leiteiras são sistemas dinâmicos que dependem de muitas operações e processos para a correta produção de leite cru de alta qualidade, ocorrendo problemas quando um desses processos está em desordem e, como resultado, haveria aumento do risco de contaminação bacteriana do leite cru.

Constatou-se que, aproximadamente 55,2\% das propriedades que continham água encanada no local de ordenha apresentaram as médias de CCS superiores ao limite estabelecido. Um dos possíveis motivos para tal fato pode estar associado a limpeza dos tetos das vacas com água antes da ordenha, que, de acordo com Fonseca e Santos (2000), tal pratica deve ser evitada sempre que possível, devendo ser utilizada apenas em casos onde as vacas cheguem à sala de ordenha com os tetos visualmente sujos (placas de esterco, barro, etc.). Andrews et al. (2008) citaram que é importante que a limpeza seja realizada com água não contaminada, uma vez que microrganismos como bactérias do grupo coliformes e Pseudomonas spp. estão associados a ocorrência de mastite, decorrentes da limpeza da glândula mamária com água contaminada.

$\mathrm{Na}$ Tabela 3 verifica-se as questões relacionadas aos direitos trabalhistas dos 37 ordenhadores contratados das 28 propriedades leiteiras localizadas no sul de Minas Gerais, e a frequência dos produtores com valores superiores aos limites de CBT e CCS estabelecidos. A satisfação com o salário, com o trabalho e o bom relacionamento com seus respectivos patrões foi relatado pela quase totalidade dos ordenhadores. Entretanto, parte desses não possuía carteira assinada, férias, $13^{\circ}$ salário, FGTS e um dia de folga durante a semana (Tabela 3). Rosa (2004) relatou que $42,9 \%$ dos 64 ordenhadores entrevistados não possuíam folga semanal e, o nível de satisfação com o trabalho foi de $69,8 \%$ (n $=104$ ordenhadores), valores distintos do presente estudo. A Constituição Brasileira de 05 de outubro de 1988 equiparou os direitos dos trabalhadores rurais e urbanos, com todos direitos e benefícios inclusos (BRASIL, 1988) e, tal desconformidade encontrada em nosso estudo, reflete a carência dos trabalhadores rurais em relação aos direitos trabalhistas.

Quando questionados se em caso de folga durante a semana, ocorriam problemas com o rebanho devido a manejo incorreto por parte do "folguista", $4(13,3 \%)$ ordenhadores responderam que sim (Tabela 3). Os problemas relatados foram: "surtos de mastite", "queda na produção", "injúrias nos animais", "interrompimento de tratamentos" e "falta de higienização dos equipamentos". O uso do "folguista" é importante, porém acaba sendo um problema grave caso este não siga os protocolos adequados. Verificou-se que, nessas propriedades, as médias de CCS também apresentaram-se superiores ao limite estabelecido, possivelmente reflexos dessas questões relatadas pelos ordenhadores. 
Tabela 2. Aspectos socioeconômicos e condições de trabalho de 37 ordenhadores contratados de 28 propriedades leiteiras de seis municípios do sul de Minas Gerais e a frequência dos produtores com valores superiores aos limites de CBT (contagem bacteriana total) e CCS (contagem de células somáticas) estabelecidos.

\begin{tabular}{|c|c|c|c|c|}
\hline \multirow[b]{2}{*}{ Questão } & \multirow[b]{2}{*}{ Averiguação } & \multirow{2}{*}{$\begin{array}{c}\text { Frequência } \\
\text { total } \\
(\mathbf{n}=\mathbf{3 7})\end{array}$} & \multicolumn{2}{|c|}{$\begin{array}{llr}\text { Frequência } & \text { de produtores com } \\
\text { valores } & \text { superiores } & \text { aos } \\
\text { parâmetros } & \text { higiênico-sanitários } \\
\text { estabelecidos } & \end{array}$} \\
\hline & & & $\mathrm{CBT}^{\mathrm{a}}(\mathrm{n}=12)$ & $\operatorname{CCS}^{b}(n=16)$ \\
\hline \multirow[t]{3}{*}{ Escolaridade } & $\begin{array}{l}\text { Analfabetismo ou apenas } \\
\text { sabiam ler }\end{array}$ & $4(10,8 \%)$ & $2(50,0 \%)$ & $2(50,0 \%)$ \\
\hline & $\begin{array}{l}\text { No máximo até o ensino } \\
\text { fundamental }\end{array}$ & $31(83,8 \%)$ & $10(32,2 \%)$ & $12(38,7 \%)$ \\
\hline & Ensino médio completo & $2(5,4 \%)$ & $0(0,0 \%)$ & $2(100,0 \%)$ \\
\hline \multirow[t]{3}{*}{ Tempo que exerce a profissão } & No máximo 10 anos & $14(38,9 \%)$ & $3(21,4 \%)$ & $4(28,6 \%)$ \\
\hline & Entre 10 e 20 anos & $13(36,1 \%)$ & $5(38,5 \%)$ & $7(53,8 \%)$ \\
\hline & Mais que 20 anos & $9(25 \%)$ & $4(44,4 \%)$ & $4(44,4 \%)$ \\
\hline \multirow[t]{2}{*}{ Recebeu treinamento? } & Sim & $14(37,8 \%)$ & $4(28,6 \%)$ & $8(57,1 \%)$ \\
\hline & Não & $23(62,2 \%)$ & $8(34,8 \%)$ & $8(34,8 \%)$ \\
\hline \multirow{2}{*}{$\begin{array}{l}\text { Caso reside na propriedade, a } \\
\text { residência tem luz, água e } \\
\text { esgoto? }\end{array}$} & Sim & $22(88 \%)$ & $9(41 \%)$ & $8(36,4 \%)$ \\
\hline & Tem luz e água somente & $3(12 \%)$ & $1(33,3 \%)$ & $1(33,3 \%)$ \\
\hline \multirow[t]{3}{*}{ Local de trabalho } & Sala de ordenha & $22(59,4 \%)$ & $6(27,3 \%)$ & $11(50 \%)$ \\
\hline & Curral coberto & $14(37,8 \%)$ & $5(35,7 \%)$ & $5(35,7 \%)$ \\
\hline & Curral descoberto & $1(2,7 \%)$ & $1(100,0 \%)$ & $0(0,0 \%)$ \\
\hline \multirow{2}{*}{$\begin{array}{l}\text { O local de ordenha possui água } \\
\text { encanada? }\end{array}$} & Sim & $29(78,4 \%)$ & $10(34,5 \%)$ & $16(55,2 \%)$ \\
\hline & Não & $8(21,6 \%)$ & $2(25,0 \%)$ & $0(0,0 \%)$ \\
\hline \multirow{2}{*}{$\begin{array}{l}\text { Existem pias com sanitizantes, } \\
\text { toalhas e demais materiais de } \\
\text { limpeza? }\end{array}$} & Sim & $31(83,8 \%)$ & $9(29,0 \%)$ & $12(38,7 \%)$ \\
\hline & Não & $6(16,2 \%)$ & $3(50 \%)$ & $4(66,7 \%)$ \\
\hline \multirow[t]{2}{*}{ Existe sanitário próximo? } & Sim & $24(64,9 \%)$ & $8(33,3 \%)$ & $10(41,7 \%)$ \\
\hline & Não & $13(35,1 \%)$ & $4(30,8 \%)$ & $6(46,1 \%)$ \\
\hline Possui todos os materiais & Sim & $36(97,3 \%)$ & $11(30,5 \%)$ & $15(44,4 \%)$ \\
\hline $\begin{array}{l}\text { necessários para a boa execução } \\
\text { de seu trabalho? }\end{array}$ & Não & $1(2,7 \%)$ & $1(100,0 \%)$ & $1(100,0 \%)$ \\
\hline
\end{tabular}

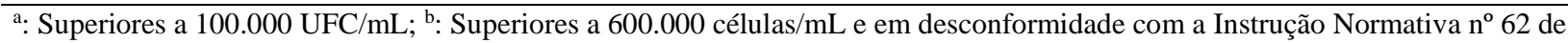
2011 durante o período estudado. Em casos onde o número de frequências difere do total dos casos, houve perda de dados. (\%): De acordo com a quantidade de casos averiguados, e não do total de casos.

Verificou-se que $80,0 \%$ dos quatro ordenadores que relataram não estarem satisfeitos com seus respectivos salários e, o ordenhador que não estava satisfeito com o trabalho, as médias de CCS do leite do tanque das propriedades apresentaram-se superiores ao limite da normativa vigente, e, respectivamente, $60,0 \%$ e $50,0 \%$ dos ordenhadores que relataram não ter pelo menos um dia de folga na semana, as médias de CBT e CCS do leite do tanque das propriedades apresentaramse superiores aos limites estabelecidos (Tabela 3). De acordo com Coda (1997), a insatisfação no trabalho pode levar a consequências desastrosas, como problemas de saúde, baixa produtividade, estresse e dificuldade de implantação de programas de qualidade.

$\mathrm{Na}$ Tabela 4 verifica-se as questões relacionadas ao comportamento dos 37 ordenhadores contratados das 28 propriedades leiteiras localizadas no sul de Minas Gerais e frequência dos produtores com valores superiores aos limites de CBT e CCS estabelecidos. A maioria dos ordenhadores higienizava adequadamente o local de ordenha; realizava a ordenha com cuidado, sem pressa e conduziam os animais calmamente ao local de ordenha (Tabela 4). A ordenha deve ser realizada por pessoas treinadas, com tranquilidade, obedecendo-se uma rotina pré-estabelecida (Philpot e Nickerson, 1991). No entanto, a maioria dos ordenhadores não higienizavam as mãos periodicamente e permitiam animais domésticos no local de ordenha (Tabela 4). De acordo com Schwabe (1984), as zoonoses constituem os riscos mais frequente à que a humanidade está exposta, relacionando-se neste contexto cerca de 150 a 180 doenças e, o leite pode ser a via de transmissão dessas doenças, caso não haja um conjunto de ações preventivas antes do seu consumo, incluindo a higienização da mão dos ordenhadores e a não permanência de animais domésticos no local de ordenha. 
Tabela 3. Aspectos socioeconômicos e condições de trabalho dos 37 ordenhadores contratados de 28 propriedades leiteiras de seis municípios do sul de Minas Gerais, e a frequência dos produtores com valores superiores aos limites de CBT (contagem bacteriana total) e CCS (contagem de células somáticas) estabelecidos.

\begin{tabular}{|c|c|c|c|c|}
\hline \multirow[b]{2}{*}{ Questão } & \multirow[b]{2}{*}{ Averiguação } & \multirow{2}{*}{$\begin{array}{l}\text { Frequência total } \\
\qquad(\mathbf{n}=37)\end{array}$} & \multicolumn{2}{|c|}{$\begin{array}{l}\text { Frequência de produtores com } \\
\text { valores superiores aos parâmetros } \\
\text { higiênico-sanitários estabelecidos }\end{array}$} \\
\hline & & & $\operatorname{CBT}^{\mathrm{a}}(\mathrm{n}=12)$ & $\operatorname{CCS}^{b}(n=16)$ \\
\hline \multirow[t]{2}{*}{ Está satisfeito com seu salário? } & Sim & $32(86,5 \%)$ & $10(31,3 \%)$ & $12(37,5 \%)$ \\
\hline & Não & $5(13,5 \%)$ & $2(40,0 \%)$ & $4(80,0 \%)$ \\
\hline \multirow[t]{2}{*}{ Está satisfeito com seu trabalho? } & Sim & $36(97,3 \%)$ & $12(33,3 \%)$ & $15(41,7 \%)$ \\
\hline & Não & $1(2,7 \%)$ & $0(0,0 \%)$ & $1(100,0 \%)$ \\
\hline \multirow{2}{*}{$\begin{array}{l}\text { Tem uma convivência harmônica } \\
\text { com seu empregador? }\end{array}$} & Sim & $35(94,6 \%)$ & $12(34,3 \%)$ & $15(42,9 \%)$ \\
\hline & Não & $2(5,4 \%)$ & $0(0,0 \%)$ & $1(50,0 \%)$ \\
\hline \multirow[t]{2}{*}{ Possui carteira assinada? } & Sim & $27(73,0 \%)$ & $9(33,3 \%)$ & $14(51,9 \%)$ \\
\hline & Não & $10(27,0 \%)$ & $3(30,0 \%)$ & $2(20,0 \%)$ \\
\hline \multirow[t]{2}{*}{ Possui férias? } & Sim & $32(86,5 \%)$ & $10(31,3 \%)$ & $14(43,8 \%)$ \\
\hline & Não & $5(13,5 \%)$ & $2(40,0 \%)$ & $2(40,0 \%)$ \\
\hline \multirow{2}{*}{$\begin{array}{l}\text { Tem pelo menos um dia de folga na } \\
\text { semana? }\end{array}$} & Sim & $27(73,0 \%)$ & $6(22,2 \%)$ & $11(40,7 \%)$ \\
\hline & Não & $10(27,0 \%)$ & $6(60,0 \%)$ & $5(50,0 \%)$ \\
\hline \multirow{2}{*}{$\begin{array}{l}\text { Caso tenha folga, ocorrem problemas } \\
\text { com o rebanho devido a manejo } \\
\text { incorreto por parte do "folguista"? }\end{array}$} & Sim & $4(13,3 \%)$ & $1(25,0 \%)$ & $4(100,0 \%)$ \\
\hline & Não & $26(86,7 \%)$ & $5(19,2 \%)$ & $7(26,9 \%)$ \\
\hline \multirow[t]{2}{*}{ Possui $13^{\circ}$ salário? } & Sim & $34(91,9 \%)$ & $10(29,4 \%)$ & $15(44,1 \%)$ \\
\hline & Não & $3(8,1 \%)$ & $2(66,7 \%)$ & $1(33,3 \%)$ \\
\hline \multirow[t]{2}{*}{ Possui FGTS? } & Sim & $22(59,5 \%)$ & $9(40,9 \%)$ & $12(54,5 \%)$ \\
\hline & Não & $15(40,5 \%)$ & $3(20,0 \%)$ & $4(26,7 \%)$ \\
\hline
\end{tabular}

a: Superiores a $100.000 \mathrm{UFC} / \mathrm{mL}$; ${ }^{\text {b: }}$ Superiores a 600.000 células $/ \mathrm{mL}$ e em desconformidade com a legislação pertinente - Instrução Normativa $n^{\circ} 62$ de 2011 durante o período estudado. Em casos onde o número de frequências difere do total dos casos, houve perda de dados. (\%): De acordo com a quantidade de casos averiguados, e não do total de casos.

Nas propriedades que possuíam ordenhadeira mecânica, constatou-se que parte dos ordenhadores forçava o conjunto de insufladores para baixo durante a ordenha (Tabela 4), para acelerar o processo de retirada do leite e evitar leite residual. Porém, esta prática ocasiona lesões nos tetos dos animais e, de acordo com Bhutto et al. (2010) estas lesões são um fator de risco para alta contagem de células somáticas no leite e infecções intramamárias nos animais. A ordenhadeira, a mão do ordenhador, práticas de higiene e lesões nos tetos são fatores que expõem a superfície dos tetos dos animais a microrganismos patogênicos contagiosos, sendo esses transmitidos de animais infectados para não infectados durante o processo de ordenha (Amaral et al., 2004). No entanto, não foi verificada alta frequência de CCS superiores ao limite estabelecido no presente estudo, nas propriedades em que tal prática era realizada.

Foi verificado que, parte dos ordenhadores $(40,5 \%)$, utilizavam antibióticos ou outros medicamentos nos animais durante a ordenha (Tabela 4). De acordo com o "Regulamento Técnico sobre as Condições Higiênico-Sanitárias e de Boas Práticas de Fabricação para Estabelecimentos Elaboradores/Industrializadores de Alimentos - Portaria MA n ${ }^{\circ} 368$, de 4 de Setembro de 1997" (BRASIL, 1997), as medidas de controle de pragas e enfermidades que, compreendem o tratamento com agentes químicos, biológicos ou físicos, devem ser aplicados somente sob a supervisão direta do pessoal que conheça os perigos potenciais que estes agentes representam para a saúde. Além disso, os prédios e instalações nas granjas leiteiras deverão ser isolados de tal maneira que permitam separar as operações susceptíveis de causar contaminação cruzada aos alimentos (BRASIL, 1997).

As propriedades nas quais os ordenhadores realizavam a ordenha apressadamente e com descuido, verificou-se que, $66,7 \%$ das médias de CCS do leite do tanque apresentaram-se superiores ao limite estabelecido e, naquelas onde os animais não eram conduzidos calmamente ao local de ordenha, $62,5 \%$ e $75 \%$ das médias de CBT e CCS do leite dos tanques, respectivamente, apresentaram-se superiores aos limites estabelecidos (Tabela 4). Tais dados revelaram o descaso de tais ordenhadores e o reflexo na qualidade do leite produzido, pois, de acordo com Rosa et al. (2009), um bom ordenhador deve apresentar temperamento calmo, sensitivo em relação aos animais, entender 
a conduta de cada animal em individual e em conjunto e as melhores formas de manejá-los e, principalmente, ter em mente a responsabilidade que seu trabalho desempenha perante a sociedade.

Tabela 4. Aspectos comportamentais dos 37 ordenhadores contratados de 28 propriedades leiteiras de seis municípios do sul de Minas Gerais e frequência dos produtores com valores superiores aos limites de CBT (contagem bacteriana total) e CCS (contagem de células somáticas) estabelecidos.

\begin{tabular}{|c|c|c|c|c|}
\hline \multirow[b]{2}{*}{ Questão } & \multirow[b]{2}{*}{ Averiguação } & \multirow{2}{*}{$\begin{array}{l}\text { Frequência total } \\
\qquad(\mathbf{n}=37)\end{array}$} & \\
\hline & & & $\mathrm{CBT}^{\mathrm{a}}(\mathrm{n}=12)$ & $\operatorname{CCS}^{b}(n=16)$ \\
\hline \multirow{2}{*}{$\begin{array}{l}\text { Higieniza adequadamente o local de ordenha } \\
\text { ao final da ordenha? }\end{array}$} & Sim & $30(81,1 \%)$ & $9(30,0 \%)$ & $14(46,7 \%)$ \\
\hline & Não & $7(18,9 \%)$ & $3(42,9 \%)$ & $2(28,6 \%)$ \\
\hline \multirow{2}{*}{$\begin{array}{l}\text { O ordenhador realiza a ordenha } \\
\text { apressadamente e com descuido? }\end{array}$} & Sim & $6(17,6 \%)$ & $2(33,3 \%)$ & $4(66,7 \%)$ \\
\hline & Não & $28(82,4 \%)$ & $10(35,7 \%)$ & $12(42,9 \%)$ \\
\hline \multirow{2}{*}{$\begin{array}{l}\text { As vacas são conduzidas calmamente ao } \\
\text { local de ordenha? }\end{array}$} & Sim & $28(77,8 \%)$ & $7(25,0 \%)$ & $10(35,7 \%)$ \\
\hline & Não & $8(22,2 \%)$ & $5(62,5 \%)$ & $6(75,0 \%)$ \\
\hline \multirow{2}{*}{$\begin{array}{l}\text { O ordenhador higieniza as mãos } \\
\text { periodicamente durante a ordenha? }\end{array}$} & Sim & $12(33,3 \%)$ & $0(0,0 \%)$ & $5(41,7 \%)$ \\
\hline & Não & $24(66,7 \%)$ & $12(50,0 \%)$ & $11(45,8 \%)$ \\
\hline \multirow{2}{*}{$\begin{array}{l}\text { O ordenhador permite animais domésticos no } \\
\text { local de ordenha? }\end{array}$} & Sim & $27(73,0 \%)$ & $7(25,9 \%)$ & $10(37,0 \%)$ \\
\hline & Não & $10(27,0 \%)$ & $5(50,0 \%)$ & $6(60,0 \%)$ \\
\hline \multirow{2}{*}{$\begin{array}{l}\text { Em caso de ordenha mecânica, o ordenhador } \\
\text { força o copo de ordenha para baixo? }\end{array}$} & Sim & $11(33,3 \%)$ & $2(18,2 \%)$ & $4(36,4 \%)$ \\
\hline & Não & $22(66,7 \%)$ & $7(31,8 \%)$ & $10(45,5 \%)$ \\
\hline \multirow{2}{*}{$\begin{array}{l}\text { Há antibióticos ou outros medicamentos no } \\
\text { local de ordenha? }\end{array}$} & Sim & $15(40,5 \%)$ & $6(40,0 \%)$ & $7(46,7 \%)$ \\
\hline & Não & $22(59,5 \%)$ & $6(27,3 \%)$ & $9(40,9 \%)$ \\
\hline \multirow[t]{3}{*}{ Higiene do uniforme do ordenhador } & $\begin{array}{l}\text { Bom a muito } \\
\text { bom }\end{array}$ & $17(45,9 \%)$ & $6(35,3 \%)$ & $8(47,1 \%)$ \\
\hline & Razoável & $15(40,5 \%)$ & $4(26,7 \%)$ & $7(46,7 \%)$ \\
\hline & $\begin{array}{l}\text { Ruim a muito } \\
\text { ruim }\end{array}$ & $5(13,5 \%)$ & $2(40,0 \%)$ & $1(20,0 \%)$ \\
\hline
\end{tabular}

a: Superiores a $100.000 \mathrm{UFC} / \mathrm{mL}$; ${ }^{\text {b }}$ : Superiores a 600.000 células $/ \mathrm{mL}$ e em desconformidade com a legislação pertinente Instrução Normativa $\mathrm{n}^{\circ} 62$ de 2011. Em casos onde o número de frequências difere do total dos casos, houve perda de dados. (\%): De acordo com a quantidade de casos averiguados, e não do total de casos.

\section{Conclusão}

Questões relacionadas com a tecnificação das propriedades estudadas (tanto alto, quanto baixo) e, algumas questões referentes às características do local de trabalho, direitos trabalhistas e comportamentais dos ordenhadores contratados e substitutos ("folguistas") apresentaram, em geral, frequências superiores aos limites estabelecidos para as médias das análises de CBT e CCS do leite nas propriedades em que tais questões não condiziam com o preconizado, tanto para a produção do leite de forma higiênica, quanto para o bem-estar dos animais e dos próprios ordenhadores.

A conscientização do treinamento da mão de obra, a verificação da efetividade dos protocolos de limpeza e regulagem dos equipamentos de ordenha e refrigeração e dos tratamentos sanitários (curativos e preventivos) dos rebanhos são medidas extremamente importantes e que devem ser trabalhadas pelos profissionais envolvidos na cadeia produtiva de leite e órgãos responsáveis.

\section{Conflito de Interesse}

Os autores declaram não existir conflito de interesse.

\section{Comitê de Ética}

Este estudo foi aprovado pela comissão de bioética e foi realizado de acordo com as normas técnicas de biossegurança e ética da Universidade Federal de Lavras, sob protocolo registrado na Plataforma Brasil, número de parecer 132.569.

\section{Referências}

Alves, E.; Mantovani, E.C.; Oliveira, A.J. Benefícios da mecanização na agricultura. Agroanalysis, 25: 38-42, 2005.

Amaral, L.A.; Isa, H.; Dias, L.T.; Rossi Jr., O.D.; Filho, A.N. Avaliação da eficiência da desinfecção de teteiras e dos tetos no processo de ordenha mecânica de vacas. Pesquisa Veterinária Brasileira, 24(4): 173-177, 2004. 
Andrews, A.H.; Blowey, R.W.; Boyd, H.; Eddy, R.G. Medicina bovina: doenças e criação de bovinos. $2^{\mathrm{a}}$ ed. São Paulo: Roca, 2008. 1080 p.

Arcuri; E.F.; Brito, M.A.V.P.; Brito, J.R.F.; Pinto, S.M.; Ângelo, F.F.; Souza, G.N. Qualidade microbiológica do leite refrigerado nas fazendas. Arquivo Brasileiro de Medicina Veterinária e Zootecnia, 58(3): 440-446, 2006.

Bardin, L. Análise de conteúdos. Lisboa: edições 70, 2003. $225 \mathrm{p}$.

Bhutto, A.L.; Murray, R.D.; Woldehiwe, Z. Udder shape and teat-end lesions as potential risk factors for high somatic cell counts and intra-mammary infections in dairy cows. The Veterinary Journal, 183(1): 63-67, 2010.

BRASIL. Constituição da República Federativa do Brasil, de 5 de outubro de 1988. Disponível em:<http://www.planalto.gov.br/ccivil_03/constit uicao/constituicao.htm>. Acesso em: 12 jan. 2017.

BRASIL. Ministério da Agricultura, Pecuária e Abastecimento. Instrução Normativa $\mathbf{n}^{0} \mathbf{5 1}$, de 18 de setembro de 2002. Disponível em: <http://www.camara.gov.br/sileg/integras/14167 3.pdf $>$. Acesso em: 12 dez. 2016.

BRASIL. Ministério da Agricultura, Pecuária e Abastecimento. Instrução Normativa $\mathbf{n}^{\mathbf{0}}$ 62, de 29 de dezembro de 2011. Disponível em: <http://www.apcbrh.com.br/files/IN62.pdf>. Acesso em: 23 out. 2016.

BRASIL. Ministério do Trabalho e Emprego. Portaria $n^{\circ}$ 86, de 3 de março de 2005. Disponível em:<http://www.mma.gov.br/estruturas/pnf/_arqui-vos/portaria_mte_86_05.pdf $>$. Acesso em: 14 de set. 2016.

BRASIL. Ministério da Agricultura, Pecuária e Abastecimento. Portaria MA no 368, de 4 de setembro de 1997. Disponível em: <http://www.cidasc.sc.gov.br/inspecao/files/2012 /08/PORTARIA-368.pdf $>$. Acesso em: 03 jan. 2017.

Coda, R. Pesquisa de clima organizacional e gestão estratégica de recursos humanos. In: Bergamini, C.W.; Coda, R. Psicodinâmica da vida organizacional. São Paulo: Atlas, 1997. p.94107.

Coentrão, C.M.; Souza, G.N.; Brito, J.R.F.; Paiva e Brito, M.A.V.; Lilenbaum, W. Fatores de risco para mastite subclínica em vacas leiteiras. Arquivo Brasileiro de Medicina Veterinária e Zootecnia, 60(2): 283-288, 2008.

Elmoslemany, A.M.; Keefe, G.P.; Dohoo, I.R.; Jayarao, B.M. Risk factors for bacteriological quality of bulk tank milk in Prince Edward Island dairy herds: part 1, overall risk factors. Journal of Dairy Science, 92(6): 2634-2643, 2009.

Fonseca, L.F.L.; Santos, M.V. Qualidade do leite e controle da mastite. São Paulo: Lemos, 2000. $314 \mathrm{p}$.

Jayarao, B.M.; Wang, L.A. A study on the prevalence of gram-negative bacteria in bulk tank milk. Journal of Dairy Science, 82(12): 2620-2624, 1999.

Lopes, M.A.; Demeu, F.A.; Costa, G.M.; Rocha, C.M.B.M.; Abreu; L.R.; Dos Santos, G.; Franco Neto, A. Influência da contagem de células somáticas sobre o impacto econômico da mastite em rebanhos bovinos leiteiros. Arquivo Instituto Biológico, 78(4): 493-499, 2011.

Mein, A.G. The role of the milking machine in mastitis control. The Veterinary Clinics of North America. Food Animal Practice, 28(2): 307-320, 2012.

Milani, M.P; Vargas, D.P.; Mello, R.O.; Nörnberg, M.F.B.L; Nörnberg, J.L. Qualidade do leite em diferentes sistemas de produção, ano e estação climática. Revista Brasileira de Ciência Veterinária, 23(3-4): 206-211, 2016.

Paixão, M.G., Lopes M.A.; Abreu L.R.; Pinto S.M. Impacto econômico da implantação das boas práticas agropecuárias relacionadas com a qualidade do leite. Revista Ceres, 61(5):612-621, 2014.

Philpot, W.N.; Nickerson, S.C. Mastitis: counter attack: a strategy to combat mastitis. Illinois: Babson Brothers, 1991. $150 \mathrm{p}$.

Rosa, M.S.; Costa, M.J.R.P.; Sant'Anna, A.C.; Madureira, A.P. Boas práticas de manejoordenha. Jaboticabal: FUNEP, 2009. 43 p.

Rosa, M.S. Ordenha sustentável: a interação retireiro-vaca. Tese de Doutorado (Zootecnia), Faculdade de Ciências Agrárias e Veterinárias UNESP, Campus Jaboticabal, 2004, 95 p.

Schwabe, C.W. Veterinary medicine and human health. $3^{\text {nd }}$ ed. Baltimore: Williams \& Wilkins, 1984. $680 \mathrm{p}$.

Souza, G.N.; Brito, J.R.F; Moreira, E.C.; Brito, M.A.V.P.; Bastos, R.R. Fatores de risco para alta contagem de células somáticas do leite do tanque em rebanhos leiteiros da Zona da Mata de Minas Gerais, Brasil. Arquivo Brasileiro de Medicina Veterinária e Zootecnia, 57(2): 251-260, 2005.

SPSS. Statistical Procedures for Social Sciences: version 17. Chicago: Survey Tips, Software, 2008. 